\title{
APLIKASI SISTEM PEMBERIAN REWARD BERDASARKAN KINERJA KARYAWAN DENGAN METODE ANALYTICAL HIERARCHY PROCESS (AHP) PADA TOKO GOLDEN JAYA STAR PEKANBARU
}

\author{
Yuda Irawan'), Nella Sari' ${ }^{2)}$, Uci Rahmalisa ${ }^{3)}$, Refni Wahyuni' ${ }^{4)}$, Yesica Devis ${ }^{5)}$ \\ 1,2,3,4 Sistem Informasi, STMIK Hang Tuah Pekanbaru, J1 Mustafa Sari No.5, \\ Tengkerang Selatan, Kec.Bukit Raya, Pekanbaru. \\ ${ }^{5}$ Kesehatan Masyarakat, STIKes Hang Tuah Pekanbaru, Jl Mustafa Sari No.5, \\ Tengkerang Selatan, Kec.Bukit Raya, Pekanbaru. \\ Email : yudairawan89@gmail.com ${ }^{1}$, nellasary9@gmail.com², \\ $\underline{\text { ucirahmalisa89@gmail.com }}{ }^{3}, \underline{\text { refniabid@gmail.com }}^{4}{ }^{\text {jejes.devis@gmail.com }}{ }^{5}$
}

\begin{abstract}
The employee reward system at the Golden Jaya Star Pekanbaru Shop is currently based on the store's personal opinion, so its assessment of employee performance is not believed to be valid. This study aims to determine the employee performance appraisal system that is right used as the basis for awarding employee rewards. There are 4 criteria used in making this decision, namely attendance, skills, communication and loyalty. This research is expected to be able to help or facilitate the Golden Jaya Star Pekanbaru Store Leader in providing rewards based on employee performance appraisal, namely the existence of this application can help leaders in providing rewards based on employee performance appraisal. With the application of the system of giving rewards based on employee performance appraisals can reduce the occurrence of errors in the provision of employee rewards. This system application is only applied to determine the amount of reward.
\end{abstract}

Keywords: applications, systems, rewards, Analytical Hierarchy Process, decision support systems

\begin{abstract}
ABSTRAK
Sistem pemberian reward karyawan pada Toko Golden Jaya Star Pekanbaru saat ini kecenderungan penilaian masih berdasarkan pendapat pribadi pimpinan toko sehingga penilaian kinerja karyawan kurang di yakini keabsahannya. Penelitian ini bertujuan untuk menentukan sistem penilaian kinerja karyawan yang tepat digunakan sebagai dasar pemberian reward karyawan. Ada 4 kriteria yang digunakan dalam pengambilan keputusan ini yaitu absensi, keterampilan, komunikasi dan loyalitas. Penelitian ini diharapkan dapat membantu ataupun memudahkan Pimpinan Toko Golden Jaya Star Pekanbaru dalam pemberian reward berdasarkan penilaian kinerja karyawan antara lain yaitu Dengan adanya aplikasi ini dapat membantu pimpinan dalam pemberian reward berdasarkan penilaian kinerja karyawan. Dengan adanya aplikasi sistem pemberian reward berdasarkan penilaian kinerja karyawan dapat mengurangi terjadinya kesalahan dalam pemberian reward karyawan. Aplikasi sistem ini hanya diterapkan untuk menentukan jumlah reward.
\end{abstract}

Kata Kunci: aplikasi, sistem, reward, analisis hirarki proses, sistem pendukung keputusan 
Hal : $87-101$

\section{PENDAHULUAN}

Pengelolaan sumber daya manusia (SDM) yang memadai diharapkan dapat turut bersaing dengan toko lain yang sejenis. Menurut Saefudin dan Wahyuningsih (2014) "Suatu organisasi atau instansi tidak terlepas dari peranan sumber daya manusia (SDM) yang bekerja di dalamnya. Kualitas sumber daya manusia merupakan salah satu faktor yang diperlukan untuk meningkatkan produktivitas kinerja suatu instansi. Oleh karena itu, suatu organisasi atau instansi perlu melakukan penilaian atas kinerja para karyawannya. Penilaian kinerja karyawan dilakukan dengan membandingkan beberapa kriteria dapat menggunakan metode Analytical Hierarchy Process (AHP). AHP dapat memecahkan permasalahan yang kompleks dengan melalui pendekatan sistem dan pengintegrasian secara deduktif. AHP menyediakan skala pengukuran dan metode untuk mendapatkan prioritas. Saat ini sistem penentuan karyawan pada beberapa perusahaan masih bersifat subjektif atau berdasarkan pada pendapat pribadi penilai yang biasanya adalah pimpinan pengambil keputusan di perusahaan tersebut.

Toko Golden Jaya Star Pekanbaru merupakan bidang usaha yang bergerak di bidang penjualan spare part, accessories, dan alat-alat service handphone serta adanya jasa service handphone yang berlokasi di Senapelan Plaza, jalan Teuku Umar lantai dasar Blok C1 No.24 Pekanbaru. Toko Golden Jaya Star Pekanbaru menekankan pada kualitas produk, kualitas pelayanan, dan kualitas waktu. Dengan keadaan yang semakin kompetitif menyebabkan toko Golden Jaya Star Pekanbaru perlu melakukan perubahan besar dalam persaingan produksi dan pengelolaan sumber daya manusia SDM. Jumlah karyawan yang ada pada toko Golden Jaya Star Pekanbaru saat ini ada sebanyak 25 karyawan yang terdiri dari 13 karyawan laki-laki dan 12 karyawan perempuan.

Kecenderungan penilaian pada toko Golden Jaya Star Pekanbaru saat ini masih berdasarkan pendapat pribadi pimpinan toko sehingga penilaian kinerja karyawan kurang di yakini keabsahannya. Oleh karena itu perlu dilakukan penilaian kinerja karyawan yang dilakukan dengan membandingkan beberapa kriteria yang akan menguraikan masalah multi kriteria yang kompleks menjadi suatu hierark. pembobotan kriteria penilaian kinerja karyawan untuk mengetahui komponen penilaian mana yang lebih penting. Pembobotan kriteria pada golden jaya star pekanbaru ada 4 (empat) antara lain yaitu berdasarkan absen, komunikasi, keterampilan, dan loyalitas. Sistem ini tidak bermaksud untuk menggantikan fungsi pimpinan toko dalam mengambil sebuah keputusan tetapi untuk membantu pimpinan toko dalam mengambil sebuah keputusan secara cepat dan tepat, sesuai dengan kriteria yang diinginkan.

\section{TINJAUAN PUSTAKA}

Aplikasi adalah penggunaan atau penerapan suatu konsep yang menjadi pokok pembahasan. Aplikasi software yang dirancang untuk penggunaan praktisi khusus, klasifikasi luas ini dapat dibagi menjadi dua yaitu:

1. Aplikasi software spesialis, program dengan dokumentasi tergabung yang dirancang untuk menjalankan tugas tertentu.

2. Aplikasi paket, suatu program dengan dokumentasi tergabung yang dirancang untuk jenis masalah tertentu.

Perangkat lunak aplikasi adalah suatu subkelas perangkat lunak komputer yang memanfaatkan kemampuan komputer langsung untuk melakukan suatu tugas yang diinginkan pengguna. Perangkat lunak aplikasi adalah pengolah kata, lembar kerja, dan pemutar media (Deslianti dan Muttaqin, 2016).

Menurut (Agusli: 2017) Sistem Pendukung Keputusan merupakan sebuah sistem (termasuk perhitungan, parameter-parameter yang terlibat, penentuan besaran nilai- 
Hal : $87-101$

nilainya, dan interaksi didalamnya atau apapun itu) mendukung ataupun menunjang (support) para pengambil keputusan (decision maker) didalam membuat keputusan (yang logis, rasional, dan terstruktur, benar) atas permasalahan yang kompleks atau semi kompleks yang terdapat begitu banyak parameter yang musti dipertimbangkan. Sistem pengambil keputusan adalah sistem berbasis komputer yang menyajikan dan memproses informasi yang memungkinkan pembuatan keputusan menjadi lebih produktif, dinamis dan inovatif.

Menurut (Pranoto: 2013) Analytical Hierarchy Process (AHP) adalah sebuah metode memecah permasalahan yang komplek atau rumit dalam situasi yang tidak terstruktur menjadi bagian-bagian komponen. Mengatur bagian atau variabel ini menjadi suatu bentuk susunan hierarki, kemudian memberikan nilai numerik untuk penilaian subjektif terhadap kepentingan relatif dari setiap variabel dan mensintesis penilaian untuk variabel mana yang memiliki prioritas tertinggi yang akan mempengaruhi penyelesaian dari situasi tersebut. AHP menggabungkan pertimbangan dan penilaian pribadi dengan cara yang logis dan dipengaruhi imajinasi, pengalaman, dan pengetahuan untuk menyusun hierarki dari suatu masalah yang berdasarkan logika, intuisi dan juga pengalaman untuk memberikan pertimbangan. SPK dengan metode Analytical Hierarchy Process (AHP) dapat menjadi solusi dalam melakukan penilaian terhadap kinerja karyawan. Peralatan utama AHP adalah sebuah hierarki fungsional dengan input utamanya persepsi manusia. Keberadaan hierarki memungkinkan dipecahnya masalah kompleks atau tidak terstruktur dalam sub - sub masalah, lalu menyusunnya menjadi suatu bentuk hierarki. Salah satu keunggulan AHP adalah dapat digambarkan secara grafis sehingga mudah dipahami oleh semua pihak yang terlibat dalam pengambilan keputusan.

\section{A. $\quad$ Prinsip Dasar Analytical Hierarchy Process (AHP)}

1. Menyusun hierarki

Penyusunan hirarki dilakukan dengan menentukan tujuan yang merupakan sasaran sistem secara keseluruhan pada level teratas. Level berikutnya terdiri dari kriteria-kriteria untuk menilai atau mempertimbangkan alternatif-alternatif yang ada dan menentukan alternatif-alternatif tersebut. Setiap kriteria dapat memiliki sub kriteria dibawahnya dan setiap kriteria dapat memiliki nilai intensitas masing-masing.

2. Penilaian kriteria dan alternatif

Dilakukan dengan menggunakan perbandingan berpasangan. Untuk berbagai persoalan, skala 1 sampai 9 adalah skala terbaik untuk mengekspresikan pendapat . Nilai dan definisi pendapat kualitatif dari skala perbandingan.

3. Synthesis of priority (menentukan prioritas)

Untuk setiap kriteria dan alternatif, perlu dilakukan perbandingan berpasangan (pairwise comparisons). Nilai - nilai perbandingan relatif dari seluruh alternatif kriteria bisa disesuaikan dengan judgement yang telah ditentukan untuk menghasilkan bobot dan prioritas. Bobot dan prioritas dihitung dengan matriks atau melalui penyelesaian persamaan matematika.

4. Logical Consistency (konsistensi logis)

Konsistensi memiliki dua makna. Pertama, objek - objek yang serupa bisa dikelompokkan sesuai dengan keseragaman dan relevansi. Kedua, menyangkut tingkat hubungan antar objek yang didasarkan pada kriteria tertentu.

B. Prosedur dalam metode AHP meliputi : 
1. Mendefinisikan masalah dan menentukan solusi yang diinginkan, lalu menyusun hirarki dari permasalahan yang dihadapi. Penyusunan hirarki adalah dengan menetapkan tujuan yang merupakan sasaran sistem secara keseluruhan pada level teratas.

2. Menentukan prioritas elemen. Langkah pertama dalam menentukan prioritas elemen adalah membuat perbandingan berpasangan, yaitu membandingkan elemen secara berpasangan sesuai kriteria yang diberikan. Matriks perbandingan berpasangan diisi menggunakan bilangan untuk merepresentasikan kepentingan relatif dari suatu elemen terhadap elemen lainnya.

3. Sintesis Pertimbangan - pertimbangan terhadap perbandingan berpasangan disintesis untuk memperoleh keseluruhan prioritas. Hal - hal yang dilakukan dalam langkah ini adalah:

a. Menjumlahkan nilai - nilai dari setiap kolom pada matriks.

b. Membagi setiap nilai dari kolom dengan total kolom yang bersangkutan untuk memperoleh normalisasi matriks.

c. Menjumlahkan nilai - nilai dari setiap baris dan membaginya dengan jumlah elemen untuk mendapatkan nilai rata - rata.

4. Mengukur Konsistensi Dalam pembuatan keputusan, penting untuk mengetahui seberapa baik konsistensi yang ada karena kita tidak menginginkan keputusan berdasarkan pertimbangan dengan konsistensi yang rendah. Hal - hal yang dilakukan dalam hal ini adalah :

a. Kalikan setiap nilai pada kolom pertama dengan prioritas relatif elemen pertama, nilai pada kolom kedua dengan prioritas relatif elemen kedua dan seterusnya.

b. Jumlahkan setiap baris.

c. Hasil dari penjumlahan baris dibagi dengan elemen prioritas relatif yang bersangkutan.

d. Menjumlahkan hasil bagi di atas dengan banyaknya elemen yang ada. Hasilnya disebut $\lambda$ maks.

5. Menghitung Consistency Index (CI) dengan rumus :

$\mathrm{CI}=(\lambda$ maks $-\mathrm{n}) / \mathrm{n}-1$

di mana $n=$ banyaknya elemen.

6. Menghitung Rasio Konsistensi / Consistency Ratio (CR) dengan rumus:

$\mathrm{CR}=\mathrm{CI} / \mathrm{IR}$

di mana $\mathrm{CR}=$ Consistency Ratio

$\mathrm{CI}=$ Concictency Index

$\mathrm{IR}=$ Indeks Random Consistency

7. Memeriksa konsistensi hirarki.

Jika nilainya lebih dari $10 \%$, maka penilaian data judgment harus diperbaiki.

Namun jika rasio konsistensi (CI/IR) kurang atau sama dengan 0,1, maka hasil perhitungan bisa dinyatakan benar.

Tabel 1 Random Index (RI)

\begin{tabular}{|l|l|l|l|l|l|l|l|l|l|l|l|l|l|l|l|}
\hline Criteria & 1 & 2 & 3 & 4 & 5 & 6 & 7 & 8 & 9 & 10 & 11 & 12 & 13 & 14 & 15 \\
\hline R.I. & 0.00 & 0.00 & 0.58 & 0.90 & 1.12 & 1.24 & 1.32 & 1.41 & 1.45 & 1.49 & 1.51 & 1.48 & 1.56 & 1.57 & 1.59 \\
\hline
\end{tabular}

Reward adalah usaha menumbuhkan perasaan diterima (diakui) di lingkungan kerja, yang menyentuh aspek kompensasi dan aspek hubungan antara para pekerja yang satu dengan yang lainnya (Siregar dan Suryalena, 2017). 
Hal : $87-101$

Sedangkan menurut (Nugroho 2006:5) Reward adalah ganjaran, hadiah,penghargaan atau imbalan yang bertujuan agar seseorang menjadi lebih giat lagi usahanya untuk memperbaiki atau meningkatkan kinerja yang telah dicapai. Dari beberapa pengertian tersebut dapat disimpulkan bahwa reward adalah pemberian balas jasa/penghargaan kepada karyawan atas hasil kerja keras mereka yang telah melewati target yang ditetapkan perusahaan. Pemberian reward diperushaan guna untuk memotivasi karyawan agar lebih giat lagi dalam bekerja.

Tujuan utama dari program reward Ivancevich dan Matteson, 2006:226 adalah :

a. Menarik orang yang memiliki kualifikasi untuk bergabung dengan organisasi.

b. Mempertahankan karyawan agar terusdatang untuk bekerja.

c. Mendorong karyawan untuk mencapai tingkat kinerja yang tinggi.

Bentuk-Bentuk Reward

Menurut Ivancevich dan Matteson:2006, Reward dibagi menjadi dua jenis yaitu :

A. Penghargaan ekstrinsik (ekstrinsic rewards)

Penghargaan ekstrinsik (ekstrinsic rewards) adalah suatu penghargaan yang datang dari luar diri orang tersebut.

\section{Penghargaan financial}

a. Gaji dan upah

Gaji adalah balas jasa dalam bentuk uang yang diterima karyawan sebagai konsekuensi dari kedudukanya sebagai seorang karyawan yang memberikan sumbangan tenaga dan pikiran dalam mencapai tujuan perusahaan atau dapat dikatakan sebagai bayaran tetap yang diterima seseorang dari sebuah perusahaan. Upah adalah imbalan yang dibayarkan berdasarkan jam kerja, jumlah barang yang dihasilkan atau banyaknya pelayanan yang diberikan.

b. Tunjangan karyawan seperti dana pensiun, perawatan di rumah sakit dan liburan. Pada umumnya merupakan hal yang tidak berhubungan dengan kinerja karyawan, akan tetapi didasarkan pada senioritas atau catatan kehadiran.

c. Bonus/insentif adalah tambahantambahan imbalan di atas atau di luar gaji/upah yang diberikan organisasi.

2. Penghargaan non finansial

d. Penghargaan interpersonal Atau biasa yang disebut dengan penghargaan antar pribadi, manajer memiliki sejumlah kekuasaan untuk mendistribusikan penghargaan interpersonal, seperti status dan pengakuan.

e. Promosi : Manajer menjadikan penghargaan promosi sebagai usaha untuk menempatkan orang yang tepat pada pekerjaan yang tepat.Kinerja jika diukur dengan akurat, sering kali memberikan pertimbangan yang signifikan dalam alokasi penghargaan promosi.

B. Penghargaan intrinsik (intrinsic rewards)

Penghargaan intrinsik intrinsic rewards adalah suatu penghargaan yang diatur oleh diri sendiri.

1. Penyelesaian (completion)

Kemampuan memulai dan menyelesaikan suatu pekerjaan atau proyek merupakan hal yang sangat penting bagi sebagian orang. Orang-orang seperti ini menilai apa yang mereka sebut sebagai penyelesaian tugas. Beberapa orang 
memiliki kebutuhan untuk menyelesaiakan tugas dan efek dari menyelesaiakan tugas bagi seseorang merupakan suatu bentuk penghargaan pada dirinya sendiri.

2. Pencapaian (achievement)

Pencapaian merupakan penghargaan yang muncul dalam diri sendiri, yang diperoleh ketika seseorang meraih suatu tujuan yang menantang.

3. Otonomi (autonomy)

Sebagian orang menginginkan pekerjaan yang memberikan hak untuk mengambil keputusan dan bekerja tanpa diawasi dengan ketat. Perasaan otonomi dapat dihasilkan dari kebebasan melakukan apa yang terbaik oleh karyawan dalam situasi tertentu.

\section{METODE PENELITIAN}

Metode yang penulis gunakan adalah metode waterfall. Secara garis besar metode waterfall mempunyai langkah-langkah sebagai berikut : Analisa, Desain, Penulisan, Pengujian dan Penerapan serta Pemeliharaan. (Kadir, 2014).

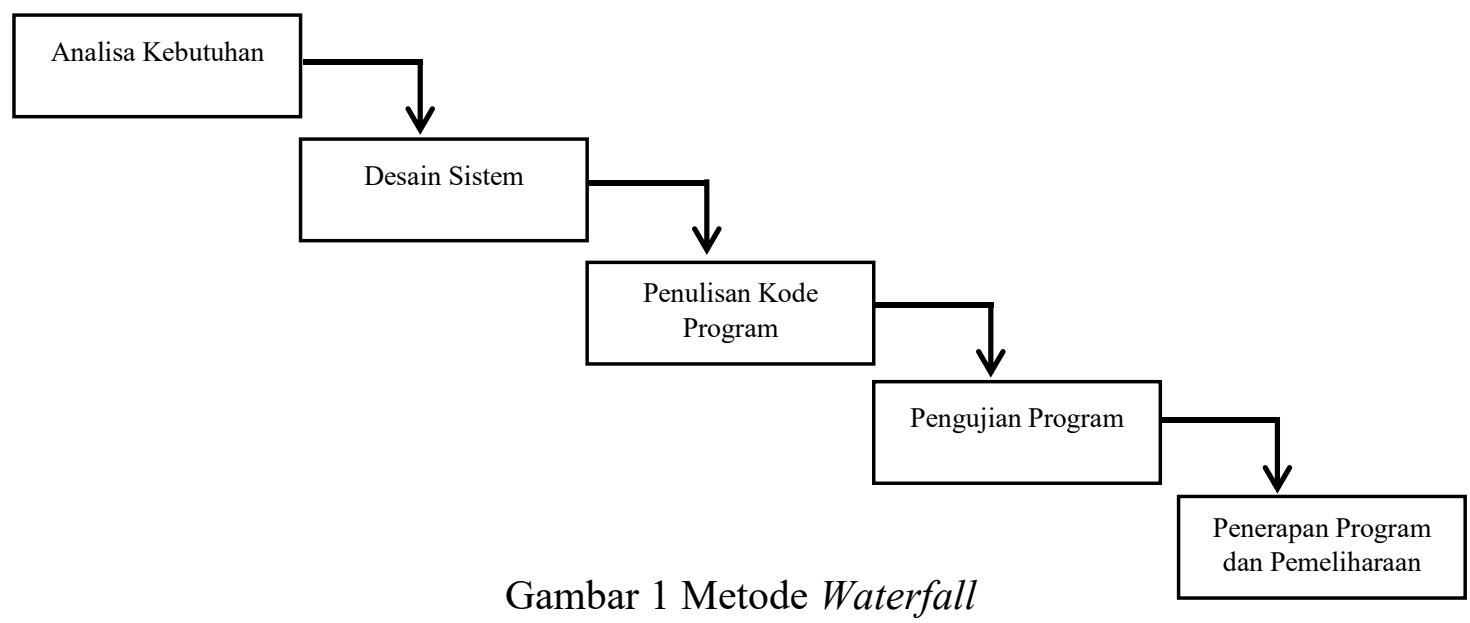

Tahapan Metode Waterfall :

\section{Analisa Kebutuhan}

Pada tahap ini peneliti melakukan analisa terhadap toko Golden Jaya Star Pekanbaru. Berdasarkan kebutuhan sistem informasi dan melakukan tahap pengumpulan data dengan melakukan pertemuan langsung dengan pihak toko yaitu kepala toko Hesti Ratna Ningsih, A.md.Kom. Setelah melakukan pemgumpulan data penulis melakukan perhitungan pemberian reward berdasarkan kinerja karyawan dengan metode analytical hierarchy process (AHP).

\section{Desain Sistem}

Tahapan setelah analisis dari kebutuhan-kebutuhan fungsional dan persiapan untuk rancang bangun implementasi menggambarkan bagaimana suatu sistem dibentuk. Pada proses desain struktur data, arsitektur sistem, representasi interface dan algoritma program.

\section{Penulisan Kode Program}

Penulisan kode program atau coding merupakan penerjemahan design dalam bahasa yang bisa dikenali oleh komputer. Tahapan ini lah yang merupakan tahapan secara nyata dalam mengerjakan suatu sistem. Tahap dimana keseluruhan desain sistem yang telah disusun sebelumnya akan diubah menjadi kode-kode program dan modul yang nantinya akan diintegrasikan menjadi sebuah sistem yang lengkap sesuai dengan yang diinginkan. 
Hal : $87-101$

\section{Pengujian Program}

Tahapan ini adalah tahap dimana aplikasi sistem pemberian reward berdasarkan penilaian kinerja karyawan yang sudah dibuat menggunakan PHP dan MySQL akan diintegrasikan dan di test untuk menguji apakah sistem telah berfungsi dengan baik.

5. Penerapan Program dan Pemeliharaan

Pemeliharaan yang termasuk diantaranya instalasi aplikasi sistem pemberian reward berdasarkan penilaian kinerja karyawan dan proses perbaikan sistem apabila ditemukan kesalahan/bug yang tidak ditemukan pada tahap testing.

\section{Teknik Pengumpulan Data}

1. Wawancara, yaitu metode pengumpulan data dengan cara berkomunikasi secara langsung dengan sumber data dan melakukan proses tanya jawab terhadap Hesti Ratna Ningsih, A.md.Kom selaku Kepala Toko yang terkait dengan tujuan memperoleh data yang lebih objektif dan dapat memperoleh jawaban yang lebih mendalam.

2. Kuisioner.

Metode kuisioner dilakukan untuk memberikan masukan terhadap besaran kriteria dan alternatif yang digunakan untuk penerapan dan pembuktian hasil analisis. Adapun jumlah responden yang dijadikan sebagai sampling berjumlah 24 responden.

3. Studi pustaka, yaitu dengan mempelajari buku-buku, referensi-referensi yang ada kaitannya dengan masalah yang dibahas untuk mendapatkan teori-teori dari permasalahan.

\section{HASIL DAN PEMBAHASAN}

\section{Analisis Sistem}

Dalam menganalisis sistem dilakukan penguraian dari suatu sistem informasi yang utuh ke dalam bagian-bagian komponennya dengan maksud untuk mengidentifikasi dan mengevaluasi permasalahan-permasalahan sehingga ditemukan kelemahan-kelemahannya, kesempatan-kesempatan, hambatan-hambatan yang terjadi dan kebutuhan-kebutuhan yang diharapkan sehingga diimplementasikan sesuai dengan harapan.

\section{Analisis Masalah}

Permasalahan yang akan dibahas adalah membuat suatu sistem berdasarkan data yang diperoleh dari Golden Jaya Star Pekanbaru, untuk mempermudah proses pembuata aplikasi sistem pemberian reward berdasarkan kinerja karyawan dengan metode AHP, maka perlu dibuatkan suatu program komputer berupa aplikasi sistem pemberian reward berbasis web.

\section{Analisis Kebutuhan Sistem}

Analisis kebutuhan sistem sangat dibutuhkan untuk menunjang penerapan sistem yang akan dibangun, apakah sistem baru yang akan diterapkan sesuai dengan kebutuhan atau sesuai dengan tujuan yang ingin dicapai. 
Hal : $87-101$

\section{Analisis pengguna}

Pengguna adalah orang yang mengoperasikan sistem, pengguna akan memanfaatkan dan berinteraksi dengan sistem. Pengguna yang akan menggunakan aplikasi sistem pemberian reward berdasarkan kinerja karyawan adalah sebagai berikut:

a. Administrator

Administrator dalam aplikasi sistem pemberian reward berdasarkan kinerja karyawan ini adalah orang yang mengelola hal-hal yang berhubungan dengan konfigurasi sistem agar dapat digunakan dengan baik. Administrator dapat menambah, mengubah, dan menghapus data dan lain-lain. Administrator pada sistem ini adalah Admin yang ditunjuk pimpinan Toko yang bertanggung jawab dengan data pemberian reward.

b. Pimpinan dan Kepala Toko

Pimpinan dan kepala toko dalam hal ini menjadi pengguna Aktif yang dapat menambah dan Mengedit data yang di tambah.

\section{Data Flow Diagram (DFD)}

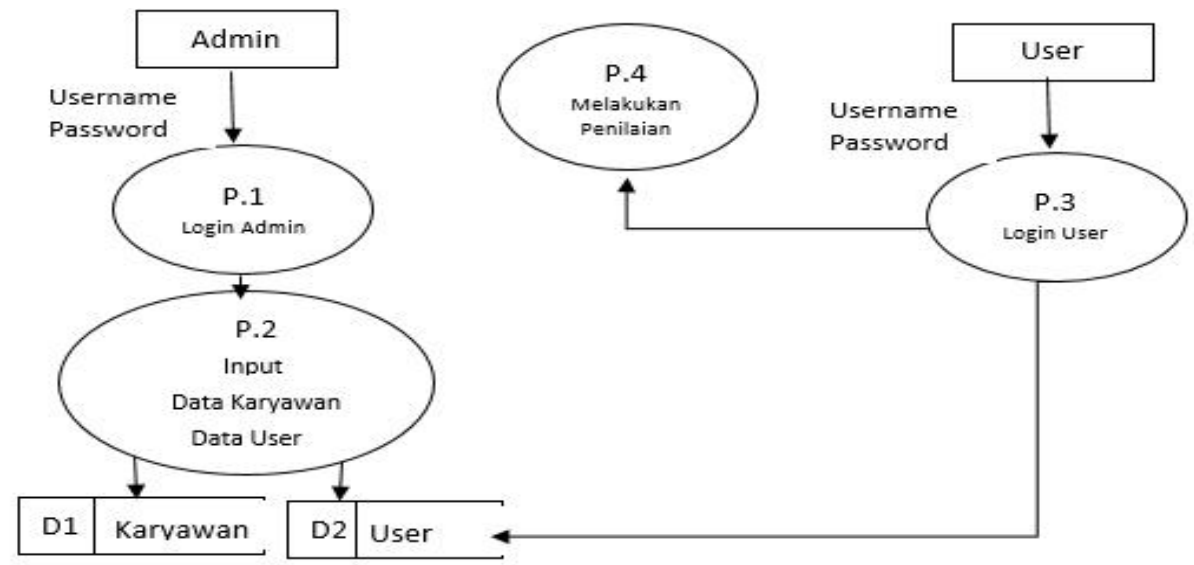

\section{Tampilan Awal Admin}

Gambar 2 Data Flow Diagram (DFD)

Halaman ini adalah halaman dimana admin harus login jika ingin menginput data karyawan, data user, jabatan dan pertanyaan. Seorang admin harus mempunyai username dan password jika ingin masuk ke halaman admin.



Gambar 3 Tampilan Awal Admin 
VOL. 2 No. 1, Juni 2019

Hal : $87-101$

\section{Tampilan Login User}

Halaman ini adalah halaman dimana user harus login jika ingin menginput Absen karyawan dan melakukan penilaian terhadap masing-masing karyawan, seorang user harus mempunyai username dan password jika ingin masuk ke halaman user.

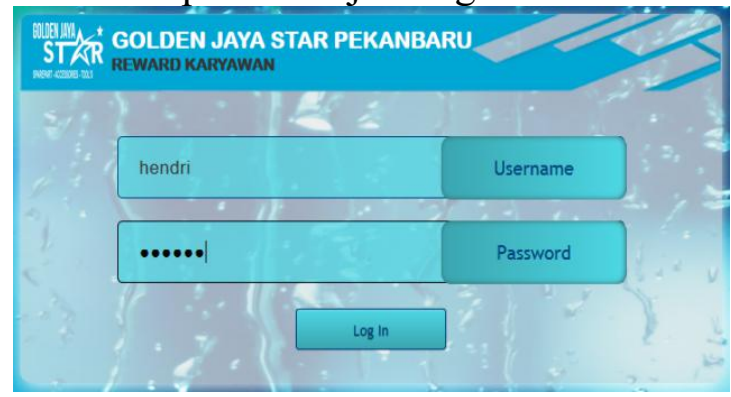

Gambar 4 Tampilan Login

\section{Tampilan Input User}

Berikut adalah tampilan input user yang dilakukan oleh admin.



Gambar 5 Tampilan Input User

\section{Tampilan Input Absensi}

Berikut ini adalah tampilan input absen yang dilakukan oleh user (kepala toko).

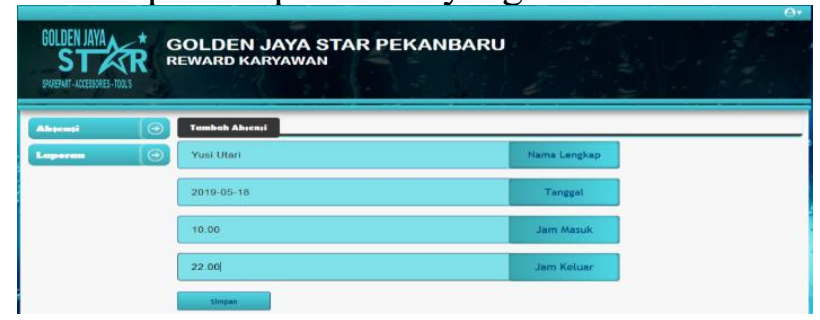

Gambar 6 Tampilan Input Absensi

\section{Tampilan Input Data Karyawan}

Berikut ini adalah tampilan input data karyawan yang dilakukan oleh admin. 


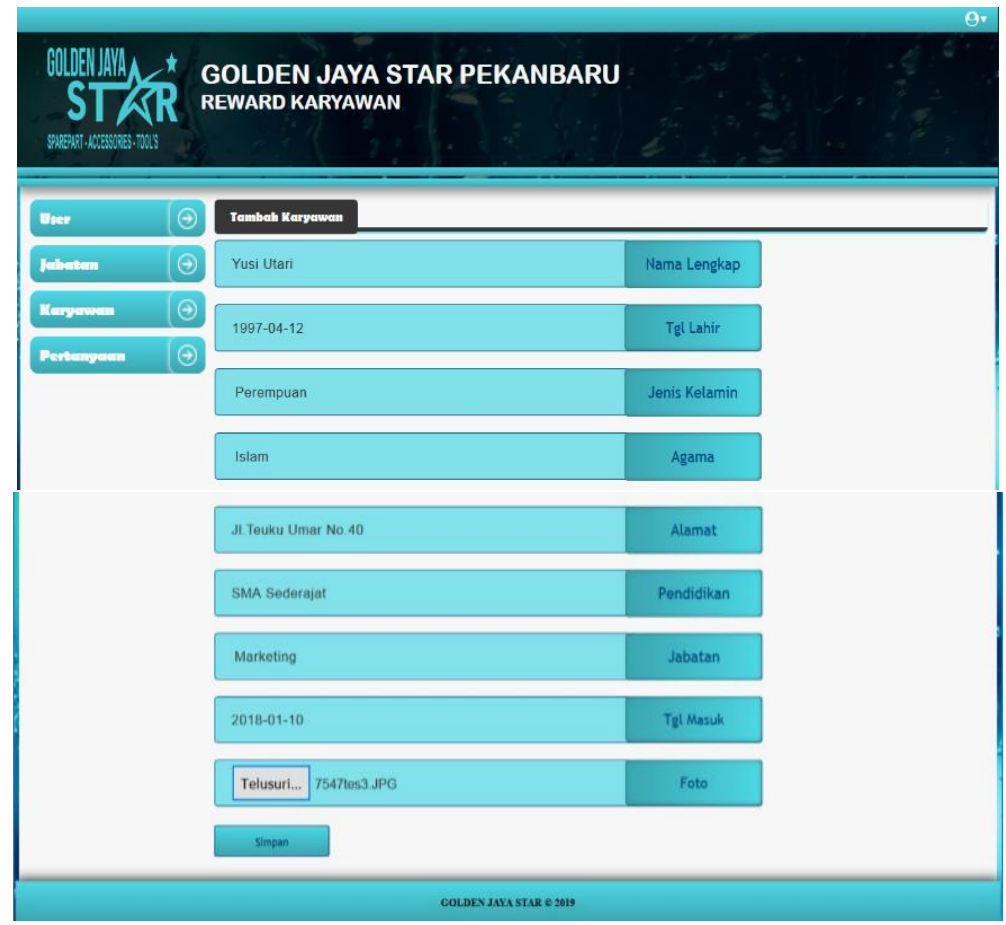

Gambar 7 Tampilan Input Data Karyawan

\section{Tampilan Input Pertanyaan}

Berikut ini adalah tampilan input pertanyaan yang dilakukan oleh admin.



Gambar 8 Tampilan Input Pertanyaan

\section{Populasi dan Sampe Penelitian}

Populasi dalam penelitian ini adalah karyawan Golden Jaya Star Pekanbaru. Pada penelitian ini, batas toleransi yang digunakan 5\%, sehingga tinggat akurasi sebesar $95 \%$. Perhitungan sampel menggunakan rumus Slovin dengan jumlah karyawan Golden Jaya Star Pekanbaru sebanyak 25 karyawan, sebagai berikut :

Rumus : $\mathbf{n}=\mathbf{N} /\left(\mathbf{1}+\mathbf{N} \mathbf{e}^{2}\right)$

$\mathrm{n}=25 /\left(1+25 \times 0.05^{2}\right)=23.5294 \approx 24$.

Dengan demikian, jumlah sampel yang dibutuhkan adalah 24 karyawan.

Penjelasan Kriteria 
Tabel 2 Penjelasan Kriteria

\begin{tabular}{|r|l|l|}
\hline No & \multicolumn{1}{|c|}{ Kriteria } & \multicolumn{1}{|c|}{ Penjelasan } \\
\hline 1 & Absen & $\begin{array}{l}\text { Menilai apakah karyawan datang dan pulang tepat } \\
\text { waktu. }\end{array}$ \\
\hline 3 & Keterampilan & $\begin{array}{l}\text { Menilai bagaimana kemampuan karyawan dalam } \\
\text { menyelesaikan pekerjaannya sehingga mendapat hasil } \\
\text { yang baik. }\end{array}$ \\
\hline 4 & Loyalitas & $\begin{array}{l}\text { Menilai tingkat komunikasi dalam penyampaian } \\
\text { fikiran, emosiaonal, dan informasi kepada rekan kerja } \\
\text { maupun pimpinan. }\end{array}$ \\
\hline
\end{tabular}

\section{Comparative Judgement (Penilaian Komparatif)}

Menentukan prioritas elemen dengan membuat matriks perbandingan pasangan untuk mendapatkan penilaian tentang kepentingan relatif dua elemen. Kemudian dituliskan dalam bentuk matriks perbandingan berpasangan (pairwise comparision). Angka-angka yang dimasukkan matriks perbandingan berpasangan diperoleh dari kuesioner yang telah diisi oleh responden. Penelitian ini menggunakan sampel 24 responden yang merupakan karyawan Golden Jaya Star Pekanbaru.

Tabel 3 Perbandingan Rata-Rata Kriteria Utama

\begin{tabular}{|l|c|c|c|c|}
\hline \multicolumn{1}{|c|}{ Kriteria } & Absen & Keterampilan & Komunikasi & Loyalitas \\
\hline Absen & 1,000 & 1,4 & 0,6 & 0,6 \\
\hline Keterampilan & 0,741 & 1,000 & 0,846 & 1,000 \\
\hline Komunikasi & 1,666 & 1,181 & 1,000 & 0,411 \\
\hline Loyalitas & 1,666 & 1,000 & 2,428 & 1,000 \\
\hline
\end{tabular}

\section{Synthesis of Priority (Sintesis Prioritas)}

Setelah matriks perbandingan berpasangan, selanjutnya dilakukan pencarian nilai rata-rata (vektor eigen atau local priority). Proses tersebut dapat dilakukan dalam langkah sebagai berikut :

a. Menjumlahkan nilai dari setiap kolom pada matriks.

b. Membagi setiap nilai dari kolom dengan total kolom yang berangkutan untuk memperoleh normalisasi matriks.

c. Menjumlahkan nilai dari setiap baris dan membagi dengan jumlah elemen untuk mendapatkan nilai rata-rata.

Tabel 4 Penjumlahan Nilai Kolom Kriteria Utama

\begin{tabular}{|l|c|c|c|c|}
\hline \multicolumn{1}{|c|}{ Kriteria } & Absen & Keterampilan & Komunikasi & Loyalitas \\
\hline Absen & 1,000 & 1,4 & 0,6 & 0,6 \\
\hline Keterampilan & 0,741 & 1,000 & 0,846 & 1,000 \\
\hline Komunikasi & 1,666 & 1,181 & 1,000 & 0,411 \\
\hline Loyalitas & 1,666 & 1,000 & 2,428 & 1,000 \\
\hline Total & $\mathbf{5 , 0 4 6}$ & $\mathbf{1 , 5 8 1}$ & $\mathbf{4 , 8 7 4}$ & $\mathbf{3 , 0 1 1}$ \\
\hline
\end{tabular}

Selanjutnya menormalisasi matriks perbandingan berpasangan dengan cara membagi nilai-nilai setiap sel dengan total nilai pada kolom yang bersangkutan. 
Tabel 5 Normalisasi Kriteria Utama

\begin{tabular}{|l|c|c|c|c|}
\hline \multicolumn{1}{|c|}{ Kriteria } & Absen & Keterampilan & Komunikasi & Loyalitas \\
\hline Absen & 0,199 & 0,305 & 0,123 & 0,199 \\
\hline Keterampilan & 0,141 & 0,219 & 0,173 & 0,331 \\
\hline Komunikasi & 0,330 & 0,257 & 0,205 & 0,137 \\
\hline Loyalitas & 0,330 & 0,219 & 0,498 & 0,332 \\
\hline
\end{tabular}

Tabel 6 Vektor Eigen Kriteria Utama

\begin{tabular}{|c|c|c|c|c|c|}
\hline Kriteria & Absen & Keterampilan & Komunikasi & Loyalitas & Rata-Rata \\
\hline Absen & 0,199 & 0,305 & 0,123 & 0,199 & 0,207 \\
\hline Keterampilan & 0,141 & 0,219 & 0,173 & 0,331 & 0,216 \\
\hline Komunikasi & 0,330 & 0,257 & 0,205 & 0,137 & 0,232 \\
\hline Loyalitas & 0,330 & 0,219 & 0,498 & 0,332 & 0,345 \\
\hline \multicolumn{5}{|c|}{ Vektor Eigen } & 1,000 \\
\hline
\end{tabular}

Dari tabel di atas terlihat bahwa :

a. Kriteria absen memiliki prioritas terendah dengan bobot 0,207.

b. Kriteria keterampilan memiliki prioritas ketiga dengan bobot 0,216.

c. Kriteria komunikasi memiliki prioritas kedua dengan bobot 0,232 .

d. Kriteria loyalitas memiliki prioritas tertinggi dengan bobot 0,345 .

Jadi urutan kriteria untuk penetapan penilaian kinerja karyawan adalah

1. Loyalitas

2. Komunikasi

3. Keterampilan

4. Absen

\section{Consistency}

Pada tahap ini akan menentukan valid tidaknya vektor eigen yang diperoleh dari proses synthesis of priority yang telah dibuat pada proses sebelumnya.

Level 1 Berdasarkan Kriteria Utama :

Berikut adalah langkah menghitung $\lambda$ maksimum :

1. Mengkalikan matriks perbandingan berpasangan yang belum dinormalisasikan dengan vektor eigen
$1,000 \quad 1,4 \quad 0,6$
0,6
0,207
0,952
$0,741 \quad 1,000$
0,846
$1,000 \quad \mathrm{x}$
$0,216=0,990$
$1,666 \quad 1,181$
1,000
1,411
0,232
1,451
1,666
1,000
2,428
1,000
0,345
2,447

2. Hasil perkaliannya dibagi dengan vektor eigen
0,952
0,207
0,95
$0,990: 0,216=0,99$
$1,451 \quad 0,232 \quad 1,45$
$2,447 \quad 0,345 \quad 2,44$ 
Hal : $87-101$

3. Bagian skalar hasil operasi penjumlahan tersebut dengan banyaknya baris atau kolom hasil akhir dijadikan sebagai nilai $\lambda$ maksimum.

$(0,95+0.99+1,45+2,44) / 4=1,457$

Langkah selanjutnya dari consistency yaitu dengan menguji konsistensi hirarki dengan cara sebagai berikut :

a. Menghitung indeks konsistensi (Consistency Index $=\mathrm{CI}$ )

Rumus CI $=(\lambda$ maks $-\mathrm{n}) /(\mathrm{n}-1)$

$(1,457-4) /(4-1)=-0,84$

b. Menghitung rasio konsistensi (consistency Ratio $=\mathrm{CR}$ )

Rumus $\mathrm{CR}=\mathrm{CI} / \mathrm{RI}$

$C R=-0,84 / 0,90=-0,93$

Nilai $\mathrm{CR}<0.1$ maka dapat diterima, artinya matriks perbandingan berpasangan level 1 berdasarkan kriteria utama telah diisi dengan pertimbangan yang konsisten dan vektor eigen yang dihasilkan dapat diandalkan.

Sistem Penilaian Kinerja Karyawan

Setelah didapatkan bobot dari setiap kriteria, maka dirancang sistem penilaian kinerja karyawan yang mampu mengurangi kelemahan dari sistem penilaian kinerja sebelumnya yang memudahkan bagi penilai untuk memberikan nilai kepada karyawan secara lebih obyektif.

Tabel 7 Skala Penilaian Kinerja Karyawan

\begin{tabular}{|c|l|}
\hline No & \multicolumn{1}{|c|}{ Keterangan } \\
\hline 1 & Sangat Kurang \\
\hline 2 & Kurang \\
\hline 3 & Cukup \\
\hline 4 & Baik \\
\hline 5 & Sangat Baik \\
\hline
\end{tabular}

Skala penilaian dikalikan dengan bobot kriteria yang telah diperoleh. Adapun format penilaian kinerja karyawan sebagai berikut :

Tabel 8 Format Penilain Kinerja Karyawan

\begin{tabular}{|l|c|c|}
\hline \multicolumn{1}{|c|}{ Kriteria } & Bobot x Nilai & Skor \\
\hline Absen & $0,207 \times \ldots$ & $\ldots$ \\
\hline Keterampilan & $0,216 \times \ldots$ & $\ldots$ \\
\hline Komunikasi & $0,232 \times \ldots$ & $\ldots$ \\
\hline Loyalitas & $0,345 \times \ldots$ & $\ldots$ \\
\hline
\end{tabular}

Laporan reward karyawan secara menyeluruh. 


\section{GOLDEN JAYA STAR PEKANBARU}

REWARD KARYAWAN

\begin{tabular}{|c|c|c|c|c|c|c|}
\hline No & Nama Lengkap & Absensi & Keterampilan & Komunikasi & Loyalitas & Reward \\
\hline 1 & Abdi & Sangat Kurang (1) & Cukup (3) & Baik (4) & Kurang (2) & Rp. 142.500 \\
\hline 2 & Ade & Sangat Kurang (1) & Kurang (2) & Cukup (3) & Baik (4) & Rp. 118.250 \\
\hline 3 & Adi & Sangat Kurang (1) & Baik (4) & Cukup (3) & Cukup (3) & Rp. 232.750 \\
\hline 4 & Afry & Sangat Kurang (1) & Kurang (2) & Baik (4) & Baik (4) & Rp. 172.250 \\
\hline 5 & Athena Yusi & Sangat Kurang (1) & Cukup (3) & Cukup (3) & Baik (4) & Rp. 204.500 \\
\hline 6 & Bowo & Sangat Kurang (1) & Sangat Baik (5) & Cukup (3) & Cukup (3) & Rp. 319.000 \\
\hline 7 & Ester Sagala & Sangat Kurang (1) & Sangat Kurang (1) & Baik (4) & Cukup (3) & Rp. 28.000 \\
\hline 8 & Fadli & Sangat Kurang (1) & Sangat Baik (5) & Baik (4) & Kurang (2) & Rp. 315.000 \\
\hline 9 & Hesti Ratna Ningsih & Cukup (3) & Sangat Baik (5) & Kurang (2) & Kurang (2) & Rp. 213.750 \\
\hline 10 & Ikhsan & Sangat Kurang (l) & Sangat Baik (5) & Baik (4) & Baik (4) & Rp. 431.000 \\
\hline 11 & Jasman & Sangat Kurang (1) & Baik (4) & Cukup (3) & Baik (4) & Rp. 290.750 \\
\hline 12 & Jepri & Sangat Kurang (1) & Baik (4) & Baik (4) & Baik (4) & Rp. $\mathbf{3 4 4 . 7 5 0}$ \\
\hline 13 & Kholil & Sangat Kurang (1) & Cukup (3) & Cukup (3) & Cukup (3) & Rp. 146.500 \\
\hline 14 & Kristina & Sangat Kurang (1) & Kurang (2) & Kurang (2) & Kurang (2) & Rp. -51.750 \\
\hline 15 & Lisa Adila & Sangat Kurang (l) & Cukup (3) & Baik (4) & Kurang (2) & Rp. 142.500 \\
\hline 16 & Munika & Sangat Kurang (1) & Sangat Baik (5) & Sangat Baik (5) & Sangat Baik (5) & Rp. 543.000 \\
\hline 17 & Putra & Sangat Kurang (l) & Cukup (3) & Kurang (2) & Baik (4) & Rp. 150.500 \\
\hline 18 & Ridel & Sangat Kurang (l) & Sangat Baik (5) & Baik (4) & Cukup (3) & Rp. 373.000 \\
\hline 19 & Serli & Sangat Kurang (l) & Sangat Baik (5) & Cukup (3) & Cukup (5) & Rp. 435.000 \\
\hline 20 & Weni & Sangat Kurang (1) & Kurang (2) & Kurang (2) & Kurang (2) & Rp. -51.750 \\
\hline 21 & Windi & Sangat Kurang (l) & Kurang (2) & Baik (4) & Kurang (5) & Rp. 230.250 \\
\hline 22 & Wulan & Sangat Kurang (l) & Baik (4) & Kurang (2) & Kurang (5) & Rp. 294.750 \\
\hline 23 & Yonathan & Sangat Kurang (1) & Kurang (2) & Baik (4) & Baik (4) & Rp. 172.250 \\
\hline 24 & Yosi Arianti & Sangat Kurang (l) & Baik (4) & Baik (4) & Baik (5) & Rp. 402.750 \\
\hline 25 & Yuli Sofia Matondang & Sangat Kurang (1) & Sangat Baik (5) & Baik (4) & Baik (5) & Rp. 489.000 \\
\hline
\end{tabular}

Pekanbaru, 26-05-2019

\section{SIMPULAN}

Adapun simpulan pada penelitian ini diharapkan dapat membantu ataupun memudahkan Pimpinan Toko Golden Jaya Star Pekanbaru dalam pemberian reward berdasarkan penilaian kinerja karyawan antara lain yaitu :

1. Dengan adanya aplikasi ini dapat membantu pimpinan dalam pemberian reward berdasarkan penilaian kinerja karyawan pada toko Golden Jaya Star Pekanbaru.

2. Dengan adanya aplikasi sistem pemberian reward berdasarkan penilaian kinerja karyawan dapat mengurangi terjadinya kesalahan dalam pemberian reward karyawan pada toko Golden Jaya Star Pekanbaru.

3. Aplikasi sistem ini hanya diterapkan untuk menentukan jumlah reward karyawan pada toko Golden Jaya Star Pekanbaru.

\section{DAFTAR PUSTAKA}

Agusli. 2017. Sistem pendukung keputusan pemberian bonus tahunan karyawan menggunakan metode TOPSIS.

Kadir, Abdul. 2014. Analisis Perancangan dan Pengembangan Sistem. Yogyakarta : ANDI.

Niagrum. 2015. Sisem pendukung keputusan pemberian bonus tahunan karyawan PT.tambora mandiri cabang dengan metode SAW. 
Hal : $87-101$

Pranoto. 2013. Rancang bangun dan analisis decision support system menggunakan metode analytical hierarchy process untuk penilaian kinerja karyawan.

Sasmito, Ginanjar. 2017. Penerapan Metode Waterfall Pada Desain Sistem Informasi Geografis Industri Kabupaten Tegal. Jurnal Informatika ISSN:2477-5126 Vol.2 No.1, Januari 2017.

Siregar dan Suryalena. 2017. Pengaruh penilaian kinerja karyawan dan reward terhadap prestasi kerja karyawan pada hotel sapadia pasir pengaraian.

Sutabri, Tata. 2012. Analisis Sistem Informasi. Andi. Yogyakarta.

Yakub, 2012. Pengantar Sistem Informasi. Graha Ilmu. Yogyakarta. 